Disclosure of Interests: Valentina Perrone: None declared, Serena Losi Shareholder of: minor stockholder at Eli Lilly, Employee of: Employed by Eli Lilly, Erica Filippi Shareholder of: minor stockholder at Eli Lilly, Employee of: Employed by Eli Lilly, Silvia Antonelli Shareholder of: minor stockholder at Eli Lilly, Employee of: Employed by Eli Lilly, Massimo Giovannitti Shareholder of: minor stockholder at Eli Lilly, Employee of: Employed by Eli Lilly, Elisa Giacomini: None declared, Diego Sangiorgi: None declared, Luca Degli Esposti: None declared

DOI: 10.1136/annrheumdis-2020-eular.1425

\section{FRI0289 DOES SMOKING AFFECT SECUKINUMAB TREATMENT OUTCOMES AND SAFETY IN PATIENTS WITH ANKYLOSING SPONDYLITIS? - REAL WORLD DATA FROM THE GERMAN AQUILA STUDY}

E. Riechers ${ }^{1}$, U. Kiltz ${ }^{2}$, J. Brandt-Juergens ${ }^{3}$, P. Kästner ${ }^{4}$, D. Peterlik ${ }^{5}$, H. P. Tony ${ }^{6}$ on behalf of the AQUILA study group. ${ }^{1}$ Medizinische Hochschule Hannover, Clinic for Immunology and Rheumatology, Hannover, Germany; ${ }^{2}$ Rheumazentrum Ruhrgebiet, Herne and Ruhr-University Bochum, Herne, Germany; ${ }^{3}$ Rheumatologische Schwerpunktpraxis, Berlin, Germany; ${ }^{4}$ Ambulantes Rheumazentrum, Erfurt, Germany; ${ }^{5}$ Novartis Pharma GmbH, Immunology, Hepatology \& Dermatology, Germany, Germany; ${ }^{6}$ Universitätsklinikum, Rheumatology/Immunology, Würzburg, Germany

Background: There is growing body of evidence that smoking is associated with more active and severe disease in patients (pts) with ankylosing spondylitis (AS). ${ }^{1,2}$ The German non-interventional study AQUILA provides real-world data on the influence of smoking on therapeutic effectiveness and safety under secukinumab (SEC), a fully human monoclonal antibody that selectively inhibits interleukin-17A.

Objectives: The aim of this interim analysis is to describe selected baseline (BL) demographics, to evaluate SEC effectiveness on disease activity and global functioning and health, and to report safety profile depending on smoking status of AS pts.

Methods: AQUILA is an ongoing, multi-center, non-interventional study including up to 2700 pts with active AS or psoriatic arthritis. Pts were observed from BL up to week (w) 52. Real-world data was assessed prospectively and analyzed as observed. Assessment of CRP and validated questionnaires were used to collect data on disease activity (Bath Ankylosing Spondylitis Disease Activity Index, BASDAI), global functioning and health (Assessment of SpondyloArthritis-Health Index, ASAS-HI) and depressive mood (Beck's Depression Inventory version II, BDI-II). For calculation of proportion of pts who experienced (serious) adverse events ((S)AEs), all AS pts were included who received at least one dose of SEC irrespective of further documentation of any study visit. This analysis focuses on the subgroups non-smoker (NS) and smoker (S).

Results: At BL, 311 AS pts were included: $42.1 \%(n=131)$ NS and $32.8 \%$ ( $n=102)$ S. Remaining subgroups were $15.1 \%(n=47)$ ex-smoker and $10.0 \%$ $(n=31)$ of unknown smoking status. About half of AS pts in NS were male, while in $S(69.6 \%)$ portion of men was more than twice as high as of women. $S$ were slightly younger than NS (mean age: $43.9 / 49.0$ years). During the study, CRP value decreased irrespective of smoking status with numerically higher fluctuations in S (Fig. 1A). BASDAI (NS: 5.2 at BL to 3.7 at w52, S: 5.6 at BL to 4.1 at w52) and ASAS-HI (Fig. 1B) scores numerically improved best in NS, whereas more variations were seen in $S$; the same was observed for BDI-II score values (NS: 11.8 at BL to 9.2 at w52, S: 13.0 at BL to 12.1 at w52). Although no major significant differences in mean values existed between NS and S, S displayed - except in w4 - overall higher mean values in the parameters mentioned above. Regarding the occurrence of AEs/SAEs with or without suspected relationship to SEC, there was no significant difference between NS and S (Table 1).

Table 1. Overview of AEs (and SAEs) under SEC treatment depending on smoking status in AS pts

\begin{tabular}{lccc}
\hline Number of pts with & NS (N=140), $\mathbf{n}(\%)$ & $\begin{array}{c}\mathbf{S}(\mathbf{N}=\mathbf{1 1 0}), \\
\mathbf{n}(\%)\end{array}$ & P value \\
\hline AE & $95(67.9)$ & $78(70.9)$ & 0.80 \\
AE with suspected relationship to SEC & $66(47.1)$ & $41(37.3)$ & 0.29 \\
SAE & $39(27.9)$ & $30(27.3)$ & 0.95 \\
SAE with suspected relationship to SEC & $15(10.7)$ & $10(9.1)$ & 0.87
\end{tabular}

Conclusion: In a real-world setting, SEC improved disease activity and global functioning and health in AS pts with slight (mostly non-significant) differences between NS and S. Overall, this interim analysis shows that SEC is an effective treatment with a favorable safety profile up to 52 weeks, irrespective of the pts' smoking status. Further progress of the AQUILA study will reveal whether this trend will continue.

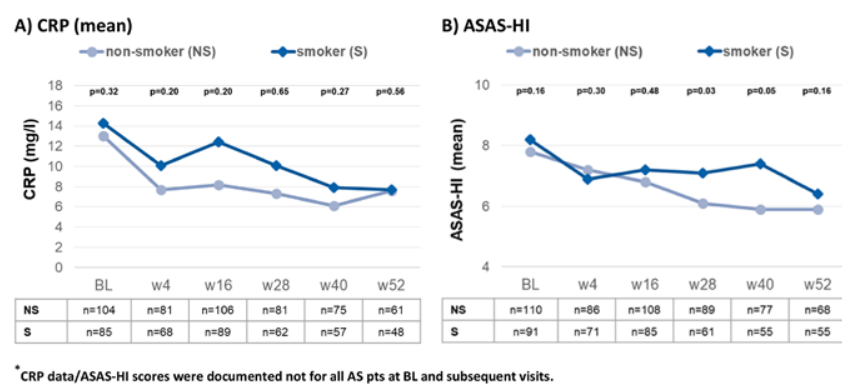

Figure 1. CRP and global functioning and health in AS pts treated with SEC depending on smoking status ${ }^{*} \mathrm{CRP}$ data/ASAS-HI scores were documented not for all AS pts at BL and subsequent visits.

\section{References:}

[1] Averns HL et al, Scand J Rheumatol 1996;25:138-42; 2. Chung HY et al, Ann Rheum Dis 2012;71:809-16

Disclosure of Interests: Elke Riechers Grant/research support from: AbbVie, Chugai, Lilly, Janssen, Novartis, Pfizer, Roche, UCB, Consultant of: AbbVie, Chugai, Novartis, UCB, Uta Kiltz Grant/research support from: AbbVie, Amgen Biogen, Novartis, Pfizer, Consultant of: AbbVie, Biocad, Eli Lilly and Company, Grünenthal, Janssen, Novartis, Pfizer, UCB, Speakers bureau: AbbVie, MSD Novartis, Pfizer, Roche, UCB, Jan Brandt-Juergens: None declared, Peter Kästner Consultant of: Chugai, Novartis, Daniel Peterlik Employee of: Novartis Pharma GmbH, Hans-Peter Tony Consultant of: AbbVie, Astra-Zeneca, BMS, Chugai, Janssen, Lilly, MSD, Novartis, Pfizer, Roche, Sanofi DOI: 10.1136/annrheumdis-2020-eular.256

\section{FRI0290 FACTORS ASSOCIATED WITH PERSISTENCE OF GOLIMUMAB TREATMENT IN THE BIOBADASER REGISTRY, UP TO 7 YEARS OF FOLLOW-UP}

M. Pombo ${ }^{1}$, C. Sánchez-Piedra ${ }^{2}$, L. Cea-Calvo ${ }^{3}$, S. Manrique Arija ${ }^{4}$, B. GarciaMagallon $^{5}$, C. Campos Fernández ${ }^{6}$, I. Notario ${ }^{7}$, F. Diaz-Gonzalez ${ }^{8}$, J. J. GomezReino ${ }^{1} .{ }^{1}$ H.C.U. de Santiago de Compostela, Santiago de Compostela, Spain; ${ }^{2}$ Sociedad Española de Reumatología, Madrid, Spain; ${ }^{3}$ Medical Affairs Dpt, MSD Spain, Madrid, Spain; ${ }^{4}$ UGC de Reumatología, IBIMA, H. Regional U. de Málaga, Málaga, Spain; ${ }^{5}$ H.G. San Jorge, Huesca, Spain; ${ }^{6}$ H.G.U. de Valencia, Valencia, Spain; ${ }^{7}$ H.U. Virgen de las Nieves, Granada, Spain; ${ }^{8}$ H.U. de Canarias, Tenerife, Spain

Background: Persistence in treatment with a biological drug can be considered an indirect measure of efficacy,safety and tolerability

Objectives: We assessed the probability of persistence of golimumab treatment in patients with rheumatic diseases and the factors associated with persistence up to 7 years of follow-up

Methods: BIOBADASER is the Spanish registry of biological drugs of the Spanish Society of Rheumatology and the Spanish Medicines Agency.A data-base analysis was done in Dec 2019 on all the patients aged 18 years or older who had initiated golimumab for rheumatoid arthritis (RA),psoriatic arthritis (PsA) and axial spondyloarthritis (SpA).The probability of persistence was calculated with a Kaplan-Meier test.Factors related to persistence were analyzed with a Cox-regression model

Results: There were 685 patients included (195 [28.5\%] RA, 294 [42.9\%] axial $\mathrm{SpA}$ and 196 [28.6\%] PsA) in the analysis (Mean age 51.3 [12.6] years, 53.7\% women). Median duration of disease at the onset of golimumab therapy was 7.6 (3.0-14.5) years. Golimumab was prescribed as first biological drug in $36.4 \%$, as second in $31.7 \%$ and as third or further in $31.9 \%$ of the patients. Concomitant medication at golimumab initiation included methotrexate $(40.0 \%)$, corticosteroids $(34.2 \%)$, leflunomide $(17.8 \%)$ and sulphasalazine $(8.1 \%)$. The probability of persistence with golimumab treatment was $71.7 \%(95 \% \mathrm{Cl} 68.1-74.9)$ at year $1,60.5 \%(56.5-64.2)$ at year 2, 55.6\% (51.5-59.5) at year 3, 50.6\% (46.2-54.8) at year $4,45.1 \%(40.1-50.0)$ at year $5,44.2 \%(39.0-49.3)$ at year 6 and $39.5 \%$ (32.8-46.2) at year 7. As the first biological agent the probability of persistence was $83.2 \%$ at year 1 and $60.0 \%$ at year 5 . As a second biological drug persistence was $70.4 \%$ and $39.9 \%$ (year 1 and 7 ). Cox-regression analysis (table) showed that the probability of persistence with golimumab treatment was higher in first vs second or third biological line (Hazard Ratio[HR] for discontinuation: 1.45 for second and 3.04 for third or further vs first line), in SpA and PsA patients (HR discontinuation vs RA:0.56 and 0.49 respectively) and in patients with methotrexate (HR:0.61) and lower in those needing corticosteroids(HR:1.71) or DMARDs different to methotrexate (HR:1.88) and in patients with higher disease activity at golimumab onset (HR:1.45)

Conclusion: The probability of persistence on golimumab therapy was high and remained relatively stable up to 7 years of follow-up. A lower risk of treatment 
discontinuation was observed in patients who received golimumab as first biological agent and in PsA and SpA patients. Persistence was lower in patients needing corticosteroids, DMARDs different to methotrexate and in those with higher disease activity at golimumab onset

\section{Cox-regression analysis.HR for discontinuation of golimumab}

\begin{tabular}{lccc}
\hline & HR & $\mathbf{9 5 \%} \mathbf{C l}$ & $\mathbf{p}$ \\
\hline Age at golimumab initiation & 1.01 & $(0.99-1.02)$ & 0.480 \\
Gender (women vs men) & 1.15 & $(0.69-1.90)$ & 0.595 \\
Smoking habit (smoker vs non-smoker) & 1.46 & $(0.90-2.37)$ & 0.128 \\
Smoking habit (past smoker vs non-smoker) & 0.94 & $(0.48-1.84)$ & 0.859 \\
Overweight (vs normal) & 1.10 & $(0.63-1.93)$ & 0.728 \\
Obesity (vs normal) & 0.90 & $(0.51-1.59)$ & 0.708 \\
SpA vs RA & 0.56 & $(0.31-1.00)$ & 0.050 \\
PsA vs RA & 0.49 & $(0.28-0.87)$ & 0.015 \\
Second vs first biological drug & 1.45 & $(0.85-2.46)$ & 0.171 \\
Third or further vs first biological drug & 3.04 & $(1.86-4.98)$ & 0.001 \\
MTX & 0.61 & $(0.38-0.97)$ & 0.037 \\
Other DMARD & 1.88 & $(0.90-3.93)$ & 0.091 \\
Corticosteroids & 1.71 & $(1.04-2.83)$ & 0.036 \\
Activity higher than median & 1.45 & $(0.96-2.19)$ & 0.078 \\
\hline
\end{tabular}

Acknowledgments: BIOBADASER is a multi-funded registry of The Spanish Society of Rheumatology (SER) and this specific analysis was funded by MSD Spain.

Disclosure of Interests: Manuel Pombo: None declared, Carlos Sánchez-Piedra: None declared, Luis Cea-Calvo Employee of: MSD Spain, Sara Manrique Arija: None declared, Blanca Garcia-Magallon Consultant of: MSD, Speakers bureau: Pfizer, Amgen, Celgene, MSD, Cristina Campos Fernández: None declared, Irene Notario: None declared, Federico Diaz-Gonzalez: None declared, Juan Jesus Gomez-Reino: None declared DOI: 10.1136/annrheumdis-2020-eular.3490

\section{\begin{tabular}{|l|l}
\hline FRI0291 SAFETY AND SURVIVAL OF SECUKINUMAB IN \\
\hline
\end{tabular} SPONDYLOARTHRITIS AND PSORIATIC ARTHRITIS: REAL-LIFE DATA. A MULTICENTER STUDY}

I. Villa-Blanco ${ }^{1}$, S. Alonso Castro ${ }^{2}$, S. Fernández ${ }^{2}$, J. L. Martín-Varillas ${ }^{1}$, L. C. Charca Benavente ${ }^{2}$, M. Pino Martínez ${ }^{2}$, L. Riancho-Zarrabeitia ${ }^{1}$, I. Morante Bolado ${ }^{1}$, M. Santos Gómez ${ }^{1}$, A. Brandy-Garcia ${ }^{3}$, E. Aurrecoechea ${ }^{1}$, L. Carmona ${ }^{4}$, R. Queiró Silva ${ }^{2} .{ }^{1}$ Hospital Sierrallana, Torrelavega, Spain; ${ }^{2}$ Hospital Universitario Central de Asturias (HUCA), Oviedo, Spain; ${ }^{3}$ Hospital Universitario de Cabueñes, Gijón, Spain; ${ }^{4}$ Instituto de Salud Musculoesquelética, Madrid, Spain

Background: Secukinumab is a human monoclonal antibody directed against IL-17A, approved for the treatment of psoriatic arthritis (PsA) and ankylosing spondylitis (AS). The safety profile of secukinumab was favourable in clinical studies, but there is still scarce evidence in clinical practice. Similarly, we currently have less data regarding the real survival of secukinumab compared to other biological therapies such as anti-TNF.

Objectives: To analyze the retention rate and safety of secukinumab as well as the causes and factors associated with its survival in patients with ankylosing spondylitis and psoriatic arthritis in real clinical practice.

Methods: we conducted a retrospective longitudinal observational multicenter study of all patients with PsA and Spondyloarthritis (SpA) who had received at least one dose of secukinumab. Adverse events and drug retention were considered the main variables. In addition, we collected variables predicting drug retention. We estimated the total adverse event rate, by severity and type of event, and drug retention (mean duration and retention at 6 months, 1 year and 2 years), all with $95 \%$ confidence intervals $(95 \% \mathrm{Cl})$. Survival was analyzed using KaplanMeier curves and predictive factors using Cox regression, with the Hazard Ratio (HR) as a measure of the association.

Results: 154 patients were included, 59 with PsA (38\%) and 95 with SpA (62\%), with a mean age of disease onset of 49 years $(S D \pm 11)$, being $55 \%$ men. The mean disease duration was 6.5 years (ICR 2-8). The median number of previous biologics was $2(S D \pm 1)$. Secukinumab was the first line of treatment in 13 patients $(8 \%)$, the second line in $46(30 \%)$, the third line in $54(35 \%)$ and subsequent lines in $41(27 \%)$. The median survival of secukinumab was 23 months (ICR 5-32), with a 1-year retention rate of $66 \%$ and a 2 -year retention rate of $43 \%$. The most frequent cause of discontinuation was inefficacy (59\%) and the second one was adverse events $(\mathrm{AE})(36 \%)$. Most patients who discontinued due to AEs ( $71 \%$ ) did so during the first 6 months of treatment. Only 2 major cardiovascular events were collected, and 2 cases of Crohn's disease occurred during the exposure. The factors identified as predictors of survival for secukinumab were: duration of disease ( $\mathrm{HR} 0.96,95 \% \mathrm{Cl}$ 0.93-0.99 $\mathrm{p}=0.012$ ), number of previous biologics (HR 1.18, 95\% Cl 1.04-1.34 $\mathrm{p}=0.011$ ), male gender (HR 0.63, 95\% Cl $0.43-0.90 \mathrm{p}=0.013)$, obesity (HR 0.31, 95\% Cl 0.18-0.54 p=0.000) and depres sion (HR 2.54, 95\% Cl 1.64-3.94 p=0.000).

Conclusion: In this study of real clinical practice, secukinumab showed a $66 \%$ retention rate at one year in a population mostly refractory to biological therapy The main cause of discontinuation was lack of efficacy. The AAs that led to drug discontinuation occurred mainly in the first 6 months of treatment

Acknowledgments: Raquel Linge, Agnes Díaz and Juan Calatayud

Disclosure of Interests: Ignacio Villa-Blanco Consultant of: UCB, Speakers bureau: Novartis, MSD, Lilly, Sara Alonso Castro: None declared, Sabela Fernández: None declared, José Luis Martín-Varillas Grant/research support from: AbbVie, Pfizer, Janssen and Celgene, Speakers bureau: Pfizer and Lilly, Lilian Consuelo Charca Benavente: None declared, Marina Pino Martínez: None declared, Leyre Riancho-Zarrabeitia Grant/research support from: Yes, Speakers bureau: Yes, Isla Morante Bolado: None declared, Montserrat Santos Gómez: None declared, Anahy Brandy-Garcia: None declared, Elena Aurrecoechea: None declared, Loreto Carmona Grant/research support from: Novartis Farmaceutica, SA, Pfizer, S.L.U., Merck Sharp \& Dohme España S.A., Roche Farma, S.A, Sanofi Aventis, AbbVie Spain, S.L.U., and Laboratorios Gebro Pharma, SA (All trhough institution), Rubén Queiró Silva: None declared

DOI: 10.1136/annrheumdis-2020-eular.5970

\section{\begin{tabular}{|l|l|l|}
\hline FRI0292 TREATMENT RESPONSE TO BIOLOGICAL \\
\hline
\end{tabular} DISEASE-MODIFYING ANTI-RHEUMATIC DRUGS IS ASSOCIATED WITH FAVORABLE CHANGES OF THE BODY COMPOSITION IN PATIENTS WITH ANKYLOSING SPONDYLITIS}

V. Rios Rodriguez ${ }^{1,2}$, M. Protopopov ${ }^{1}$, F. Proft ${ }^{1}$, J. Rademacher ${ }^{1,2}$, B. Muche ${ }^{1}$, A. K. Weber ${ }^{1}$, S. Lüders ${ }^{1}$, H. Haibel ${ }^{1}$, M. Verba ${ }^{1}$, J. Sieper ${ }^{1}$, D. Poddubnyy ${ }^{1,3}$ ${ }^{1}$ Charité - Universitätsmedizin Berlin, Berlin, Germany; ${ }^{2}$ Berlin Institute of Health, Berlin, Germany; ${ }^{3}$ Deutsches Rheuma-Forschungszentrum (DRFZ), Berlin, Germany

Background: There is few data available regarding differences in body composition and its possible changes in patients with ankylosing spondylitis (AS) treated with biological disease-modifying anti-rheumatic drugs (bDMARDs). An increase of body weight and lean mass in patients receiving TNF inhibitors, as well as a possible muscle wasting by high disease activity have been previously described. Bioelectrical impedance analysis (BIA) is a valid method to assess body composition and allows to distinguish between fat, fat-free mass and skeletal muscle mass.

Objectives: To evaluate changes in body composition in patients with AS after 6 months of treatment with bDMARDs.

Methods: Patients with a diagnosis of AS, fulfilling the modified New York criteria and starting a bDMARD therapy were included in the extension of the prospective German Spondyloarthritis Inception Cohort (GESPIC). All patients had high disease activity (BASDAI $>=4$ and/or ASDAS $>=2.1$ ) despite previous treatmen with nonsteroidal anti-inflammatory drugs. Disease activity and body composition were assessed at baseline and after 6 months of bDMARD treatment. Body composition was assessed by the BIA with the seca@ mBCA 515 device (SECA Deutschland $\mathrm{GmbH}$, Hamburg/Germany) and included the following parameters: weight, body mass index (BMI), fat mass index (FMI), fat free mass index (FFMI), skeletal muscle mass value (SMM), and visceral adipose tissue value (VAT). Response to a bDMARD therapy was defined as achievement of clinically important improvement of ASDAS (>=1.1).

Results: A total of 129 patients $(66.7 \%$ male) with AS were recruited in this cohort extension between 2015 and 2019. The mean (mean \pm SD) age was 36.2 \pm 10.3 years, and symptom duration was $10.7 \pm 9.1$ years. HLA-B27 test was positive in $89.1 \%$ patients. BIA was assessed in 77 patients; the baseline characteristics of these patients were similar to those of the whole cohort. Of these 75 patients were treated with TNF inhibitors and 2 patients were treated with an IL-17A inhibitor

After 6 months of a bDMARD treatment, body composition changed significantly with an increase of weight and BMI due to the gain of FMI but also of FFMI and SMM, while there was no increase of the visceral fat - table. In responders (improvement of ASDAS>=1.1 after 6 months) the results were similar to the whole group with a significantly gain $($ mean $\pm S D$ ) on BMI, FMI, FFMI and SMM $\left(0.3 \pm 1.4 \mathrm{~kg} / \mathrm{m}^{2}, 0.3 \pm 1.0 \mathrm{~kg} / \mathrm{m}^{2}, 0.2 \pm 0.5 \mathrm{~kg} / \mathrm{m}^{2}, 0.5 \pm 1.2 \mathrm{~kg}, \mathrm{p}<0.05\right.$, respectively). In non-responders, there were no significant changes on the body composition after 6 months of treatment.

Conclusion: Treatment with bDMARDs is associated with favorable changes of the body composition with increase of the muscle mass but not of the visceral fat. These changes were evident in treatment responders only. 